\title{
A propósito del estudio histórico necesario a la organización de los Fondos Judiciales*
}

\section{The historical study needed for the organization of Judicial Funds}

\author{
IVONNE SUÁREZ PINZÓN \\ Doctora en historia y archivista., Profesora Titular de la Escuela de Historia, Facultad de Ciencias Humanas, Universidad \\ Industrial de Santander,. \\ isuarez@uis.edu.co \\ Ciudad Universitaria UIS, Calle 9 Carrera 26a. Facultad de Ciencias Humanas, Escuela de Historia \\ Bucaramanga-Colombia \\ LUIS CARLOS MATEUS CORZO \\ Historiador y Archivista. Investigador Universidad Industrial de Santander, Colombia. \\ lwizka@gmail.com
}

LAURA P. ROJAS VILLAMIZAR

Historiadora y Archivista. Investigadora Universidad Industrial de Santander, Colombia. laura.rojas.arch@gmail.com

Para citar este artículo

Suárez Pinzón, I; Mateus Corzo, L \& Rojas Villamizar, L. (2015). A propósito del estudio histórico necesario a la organización de los Fondos Judiciales Justicia Juris, 11(1), 26-39.

Recibido: Octubre 15 de 2014

Aceptado: Febrero 26 de 2015

\section{RESUMEN}

La necesidad de preservar como patrimonio documental y para la investigación social los expedientes judiciales producidos a lo largo del siglo XX por las diferentes entidades del poder judicial en Santander, pone de manifiesto el importante diálogo que para dicho propósito deben llevar a cabo la Historia y la Archivística. El presente artículo es resultado de ese diálogo y de la investigación realizada mediante él. Se exponen aquí, los cambios experimentados por las instituciones judiciales, en cuanto a organización territorial se refiere, en el Departamento de Santander-Colombia- a lo largo de más de siete décadas, en un periodo comprendido entre 1886 y 1965, y la dinámica histórica de las instituciones que sirvieron de auxiliares al poder judicial en su tarea de recabar evidencias en los procesos de carácter penal. Estos avances investigativos constituyen un aporte trascendental tanto al conocimiento histórico de las instituciones del poder judicial en Santander como a la tarea archivística de organizar el acervo documental producido por éstas; además de dejar explícita la riqueza y variedad de la información que contienen los expedientes judiciales para la investigación social en general.

Palabras clave: Administración de justicia; Cuerpo auxiliar de la Institución judicial; División territorial judicial; Distrito Judicial; Expediente judicial; Organización documental.

* El presente artículo es resultado del proyecto de investigación titulado: Organización de fondos judiciales del archivo histórico regional de la UIS y aportes a la construcción de la memoria histórico-judicial como patrimonio regional y nacional, fase 2, financiado por la Vicerrectoría de Investigaciones de la Universidad Industrial de Santander. 


\begin{abstract}
The need to preserve as documentary legacy and for social research the judicial records produced throughout the 20th century by different entities of the judiciary in Santander reveals the important dialogue that for this purpose should conduct History and Archival Science. The present text is the result of a research. Describe here, the changes experienced by the judicial institutions, in terms of territorial organization it refers, in the Department of Santander throughout more than seven decades, in a period from 1886 to 1965, and historical dynamics of the institutions which served as auxiliaries to the judiciary in its task of gathering evidence in the processes of criminal records. This research constitutes a transcendental contribution to both, the historical knowledge of the institutions of the judiciary in Santander and the task of organizing archival documentary heritage produced by these; besides there is a variety of information contained in court records for social research in general.
\end{abstract}

Keywords: Justice Administration; Auxiliary Corps of judicial institution; Territorial Judicial division; Judicial District; Court documents; Documentary Organization.

A manera de introducción: Notas sobre la importancia de los expedientes judiciales

Los diversos tipos de documentos que se ordenan para conformar los expedientes judiciales han llegado a servir como una de las fuentes más ricas en información sobre la realidad social y así, una invaluable materia prima para la investigación histórica, y pudieran ser, sin duda, un importante instrumento heurístico de otras áreas de las ciencias sociales como la antropología, la sociología y el derecho. Pero en el sentido más inmediato, el acervo de documentación que se produce en relación con la actividad cotidiana de la institucionalidad judicial del Estado, cuyo documento central es el expediente judicial, constituye el soporte de la memoria de estas instituciones y de la aplicación de justicia en una sociedad.

A los documentos judiciales pueden planteárseles entre otras preguntas, las referidas a la vida de sectores sociales que no tienen mayor expresión documental en otros acervos, tales como campesinos, obreros, trabajadoras domésticas, prostitutas, amas de casa, niños que delinquen, etc. En estos documentos se reflejan las motivaciones y condiciones sociales e individuales presentes en la comisión de conductas calificadas como delictuosas por las instituciones del Estado y la forma como son evaluadas y sancionadas por los jueces, así como las expresiones diversas de los conflictos sociales en el terreno económico, cultural y en el ámbito de la lucha de clases; evidenciándose las diferenciación de los individuos en relación con el lugar ocupado en la sociedad, es decir, en cuanto a riqueza acumulada, ingresos y status social, y los conflictos asociados a ello; y además, en esta documentación se evidencia la intervención del aparato de justicia del Estado para resolver las diferentes colisiones sociales, en el marco de su papel de asegurar el mantenimiento del status quo en cuanto a su ordenamiento civil y a la aplicación de la ley para castigar el delito. En resumen se puede decir que es inimaginable la gran constelación de aspectos de la realidad económica y socio-cultural sobre la cual los expedientes judiciales permiten indagar. El expediente judicial es la evidencia documental de un proceso dirigido por una institución del Estado encargada de la aplicación de justicia y en la cual toman parte diferentes actores sociales involucrados de diversas maneras en pleitos de carácter civil, en conductas delictuosas o en conflictos laborales, cuyo propósito es construir una "verdad procesal" para dar soporte a la decisión de la autoridad judicial.

En términos documentales, el expediente judicial es un conjunto de documentos ordenados bajo criterios legales y la supervisión de entidades investidas de autoridad policial o judicial. Para la organización documental y el estudio de los expedientes judiciales se requiere conocer la legislación y normatividad y sus cambios en el tiempo, referidos a la organización judicial del territorio, a las competencias de conocimiento de procesos de orden civil o penal y a los procedimientos establecidos para sustentar las decisiones de las diferentes autoridades encargadas de administrar justicia.

Por su propia naturaleza, el expediente judicial ha sido construido con la intervención de varias manos: Allí están las voces de personas de los secto- 
res sociales quienes responden a indagatorias, en calidad de sindicados de delitos, o como testigos que rinden declaratoria o entablan demandas o denuncias penales. Allí está la participación de los abogados que elevan memoriales a las autoridades judiciales o ejercen la defensa en las audiencias. También aparecen en los expedientes judiciales dictámenes de medicina legal, constancias de procedimientos de cateo o elaboración de croquis y toma de fotografías por parte de autoridades de policía. Finalmente, otros protagonistas en el expediente judicial son los mismos jueces, fiscales y magistrados, que mediante autos y conceptos van dirigiendo y definiendo el rumbo y conclusión de los procesos. En razón de lo anterior, otra de las exigencias en el tratamiento archivístico de los expedientes judiciales y en su uso para la investigación social es el conocimiento de los diversos tipos documentales que crean esas diferentes intervenciones y su ubicación en relación con el propósito central del proceso del que son expresión concreta. En concordancia con lo expresado, en este artículo se busca exponer algunos aspectos en el conocimiento adquirido a través de la investigación sobre la organización de la administración de justicia en el Departamento de Santander, Colombia, particularmente lo concerniente a la división territorial judicial y a las instituciones que componen el Cuerpo Auxiliar de la Institución judicial. Todo ello, visto en perspectiva de los cambios que a lo largo del período de estudio se han observado.

El proyecto de organización e investigación de los fondos judiciales que reposan en el Archivo Histórico Regional de la Universidad Industrial de Santander

A pesar de la importancia de la documentación judicial, miles de expedientes y series documentales producidas por las instituciones del poder judicial suelen arrumarse en las peores condiciones de conservación en los depósitos de los Palacios de justicia y de los juzgados del país, sufriendo grave deterioro y estando en evidente riesgo de desaparición. En ese preocupante contexto, han constituido una apreciable labor de recuperación patrimonial las acciones que se han puesto en marcha desde la academia, con el propósito de preservar, organizar, investigar y poner a disposición de la consulta de los ciudadanos una parte de este gran acervo documental. Se quieren destacar aquí las tareas avanzadas en la recuperación de estos fondos por las universidades Pedagógica y Tecnológica de Colombia- UPTC, en Tunja (Wiesner 2002, pp.6980), la Universidad Nacional, sede Medellín (Palacio, 2002, pp. 315-320) y la Universidad Industrial de Santander (en adelante UIS), en la ciudad de Bucaramanga.

Para esta última pueden establecerse dos momentos. El primero, a inicios de la década de 1990, que tras la labor de un grupo de historiadores de la UIS y de académicos ligados con el Centro de Investigaciones de la Universidad Autónoma de Bucaramanga, UNAB y la Oficina de la Carrera Judicial de Bucaramanga, logró recuperar parte de la documentación del Palacio de Justicia de Bucaramanga que reposaba en el sótano de esa institución. Así, en 1991 el Centro de Documentación e Investigación Histórica Regional, adscrito a la Facultad de Ciencias Humanas de la UIS, el Centro de Investigaciones de la UNAB y la Oficina de la Carrera Judicial de Bucaramanga firmaron un convenio para custodia, estudio, restauración y mantenimiento de archivos históricos de la rama jurisdiccional. De manera que, en la UIS los historiadores iniciaron su organización basados en el sistema de clasificación temática, sin aplicar los principios archivísticos que entonces se desconocían en la institución. Clasificaron entonces el acervo de expedientes tomando como criterio los delitos o los procesos civiles a los cuales correspondían.

El segundo momento, es el proceso de reorganización de los archivos históricos judiciales que desde el 2012 adelantan los autores de este escrito, directora y miembros del grupo de investigación Historia, Archivística y Redes de Investigación, en un proyecto que interviene parte de la documentación transferida a la UIS en 1991. Dados los criterios aplicados para clasificar y ordenar en la mayoría de las experiencias mencionadas de recuperación de archivos judiciales, los autores de este proyecto se propusieron organizar los fondos judiciales basados en los principios archivísticos básicos: el principio de procedencia y el orden natural, para lo cual se hizo necesario reestructurar el organigrama institucional de los entes productores mediante la investigación de la memoria e historia institucional del Poder Judicial en Santander. De esta manera, de un total de trescientos sesenta metros lineales de expedientes judiciales recibidos por la UIS a principios de los 90, el equipo ha organizado setenta metros lineales, que comprenden casi siete mil expedientes, que, en su mayoría, debido a la anterior clasificación, corresponden a los delitos de lesiones personales (delito que antes de 1937 se denominaba heridas, golpes y malos tratamientos), robo, hurto y homicidio; todos ellos son procesos seguidos por diversos juzgados de los diferentes Distritos Judiciales que operaron en Santander desde 1887 hasta 1965. 
Cambios en la organización de la institución judicial 1887-1965

El cambio político y administrativo que significó la disolución de la organización federal del territorio de Colombia después de la Guerra Civil de 1885 y del triunfo del programa político de la Regeneración ${ }^{1}$, implicó a su vez la unificación nacional de la legislación y la normatividad para el funcionamiento de la administración de justicia en todo el territorio. Para ello, el Congreso Nacional estableció en el año de 1887, que esta rama del poder público se regiría en toda Colombia mediante un solo Código Civil que había sido sancionado en el año de 1873, un mismo Código Penal que había regido para el antiguo Estado de Cundinamarca, sancionado en el año de 1858, y un único Código Judicial sancionado en el año de 1872. (Congreso Nacional, Ley 57 de 1887).

Además de la unificación legislativa, otros cambios se operaron en la estructura de la organización judicial en el territorio de los antiguos Estados soberanos. En cuanto al Estado de Santander, en julio de 1886 la administración de justicia tenía su principal instancia en el Juzgado del Estado, cuya sede se hallaba en la ciudad de San Gil. En los distintos departamentos que conformaban el territorio del Estado tenía asiento un Juzgado Superior del Departamento, con sede en la capital de cada uno de ellos. Finalmente en la base de esta estructura se encontraban los Juzgados de distrito. Cuando hacia el mes de octubre de ese mismo año, el Estado de Santander pasó a ser Departamento de la República de Colombia, antes de la unificación legislativa comentada arriba, los tres niveles se vendrían a denominar: Juzgado del Departamento, Juzgado Superior de la Provincia y Juzgado Municipal.

Estos cambios en las denominaciones de los juzgados evidencian un período de transición que dio inicio en el año de 1886 y que tardaría en consolidarse por lo menos hasta la segunda década del siglo XX. La manera en que dichos cambios operaron y el tiempo que tardaron son reflejo de las con-

1 El objetivo de los regeneradores era garantizar el orden del país, el cual se apoyaría en elementos básicos como la centralización del poder público, el fortalecimiento de los poderes del Ejecutivo, el apoyo a la Iglesia y al catolicismo como fuerzas educativas y de control social. Por medio de la Constitución de 1886 , los representantes políticos de La Regeneración consagraron el carácter unitario de la nación, ordenaron que la legislación penal, civil, comercial, minera, etc., fuese de orden nacional, y eliminaron la elección de funcionarios ejecutivos regionales, dejando su designación a cargo del Presidente de la República. En cuanto a lo fiscal, los departamentos conservaron algunas rentas pero la mayoría pasaron a ser dirigidas por el gobierno central. tradicciones de la época, por un lado la resistencia de parte de los sectores dominantes en los Estados a la centralización del poder público, lo cual incluía la lucha por mantener algún margen de soberanía en su territorio; por otro, puede colegirse un tiempo de negociación de los intereses en conflicto para concretar una organización del territorio nacional ahora unificado, entre otras cosas, en cuanto a la administración de justicia.

El Distrito Judicial fue la unidad básica territorial para la división de la jurisdicción de la administración de justicia que se estableció formalmente en toda la República en el artículo 152 de la Constitución de 1886. El Distrito Judicial ha sido un espacio físico cuyos límites establecen la jurisdicción de un Tribunal de magistrados, el Tribunal Superior y un Juzgado o varios Juzgados Superiores. El Distrito Judicial ha estado conformado a su vez por Circuitos Judiciales, en donde han tenido jurisdicción los Juzgados de Circuito. Finalmente, los circuitos han agrupado a los municipios, con sus respectivos juzgados municipales.

La organización del territorio en Distritos y Circuitos judiciales fue una medida administrativa que, con el paso del tiempo, fue posibilitando la separación de la administración de justicia del marco jurisdiccional de los departamentos y sobre todo del de la antigua Provincia, aunque inicialmente las fronteras de esta entidad administrativa y las del Circuito judicial coincidieran plenamente. Esto probablemente le dio a la administración de justicia mayor flexibilidad para remontar las dificultades que le presentaban las escasas comunicaciones, pero más seguramente configuró un espacio específico y relativamente independiente de resolución de los conflictos entre las clases dominantes a nivel local y regional.

En el caso del Departamento de Santander, en términos de la aplicación de justicia, la administración de su territorio estuvo disputada por las ciudades de San Gil y Bucaramanga. Así, para el año de 1887 la sede del Distrito Judicial que gobernaba judicialmente el Departamento cambió de la primera a la segunda ciudad, cambiando su denominación. Para el año de 1888 el territorio fue dividido en dos distritos judiciales (Congreso Nacional, Ley 30 de 1888): del Norte y del Sur, el primero con sede en Bucaramanga, el segundo en el Socorro, otra ciudad que históricamente le había disputado a esta ciudad su primacía en el Departamento (V. Imagen 1). 


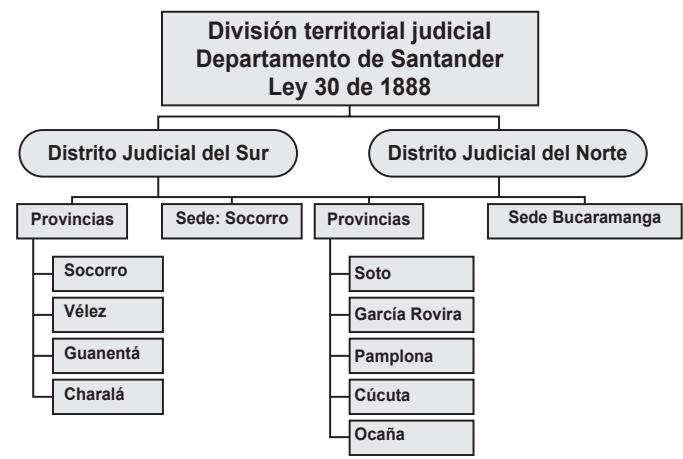

\section{Imagen 1. Esquema de la división territorial judicial del Departamento de Santander, desde el $1^{\circ}$ de abril de 1888}

En este período de la llamada Regeneración, la administración del territorio en cuanto a lo político y lo judicial evidenciaba los conflictos de poderes ligados al necesario ajuste institucional luego de casi medio siglo de organización federal. Para el año de 1905, el territorio del Departamento de Santander había sido dividido en dos nuevos departamentos: Galán, cuya capital era la ciudad de San Gil, compuesto por las provincias de Socorro, Vélez, Guanentá y Charalá; y Santander, con su capital en Bucaramanga, y conformado por las provincias de Soto, García Rovira, Pamplona, Cúcuta y Ocaña.

En ese mismo año (Congreso Nacional, Ley 63 de1905), el Congreso de la República pretendió mantener la división territorial judicial de los distritos judiciales Norte y Sur, ahora con las nuevas denominaciones de Santander y Galán. Sin embargo, un año más tarde mediante Decreto, argumentando limitaciones económicas en la administración del Estado, el Poder Ejecutivo suprimía el Distrito Judicial de Galán, junto con otros más en diferentes partes del país, y ampliaba la jurisdicción del de Santander (Diario Oficial, 1906, Decreto presidencial $\mathrm{N}^{\circ} 41$ ), retornando a la situación anterior a 1888. Así, El Distrito Judicial de Santander quedaba comformado por los circuitos de Bucaramanga, Cúcuta, Málaga, Ocaña, Pamplona, Salazar, Charalá, Guanentá, Socorro, Vélez y Zapatoca. Los problemas de solvencia financiera se combinaban con las necesidades de una administración más eficiente en la aplicación de justicia, pero también con las luchas de poderes, en este caso materializadas en la rivalidad de ciudades por mayor independencia en la administración de esta rama del poder político. Suprimir un Distrito Judicial en concreto significa suprimir un Tribunal Superior, lo cual implica ahorro de pagos a servidores públicos de alto nivel, pero también conlleva restar poder a un centro político regional y acrecentar los problemas de eficiencia que presentaban las serias dificultades en el transporte de la época. El Gobierno resolvió ese triple problema nombrando un Juzgado $2^{\circ}$ Superior del Distrito Judicial de Santander y trasladando su residencia a la ciudad de San Gil. Sin embargo, sólo un año después, el Congreso Nacional (Congreso Nacional, Ley 32,1907) volvió a establecer el Distrito Judicial de Galán con sede en San Gil y retornó a las jurisdicciones establecidas en 1888, para los Distritos Judiciales de Galán y Santander, con unos cambios en la creación de nuevos circuitos (V. Imagen 2).

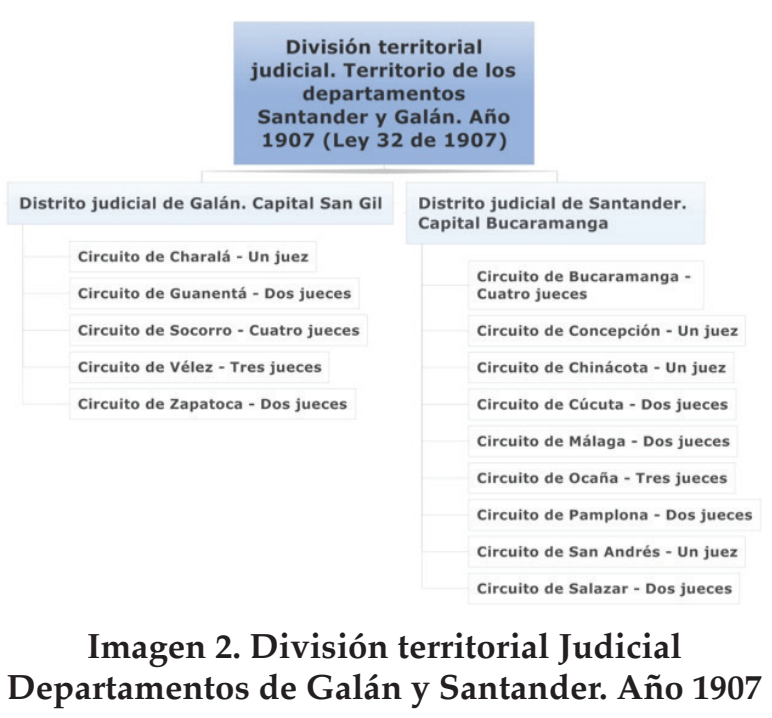

Pero ahí no terminaron los ajustes de la trancisión. Aún debía delinearse definitivamente el territorio del Departamento de Santander y, con él, las jurisdicciones judiciales correspondientes. En el año de 1909 se restableció el anterior espacio territorial del antiguo Estado, con la desaparición del Departamento de Galán, pero en el año de 1910 se escindieron de él las provincias de Pamplona, Cúcuta y Ocaña, para formar el Departamento de Norte de Santander, con capital en la ciudad de San José de Cúcuta, impulsando un cambio en la división territorial judicial. En septiembre de 1912 (Congreso Naciona, Ley 23, 1912) se estableció la definitiva delimitación de los dos distritos judiciales que administraban justicia en el territorio de Santander: los Distritos Judiciales de San Gil y Bucaramanga (V. Imagen 3). 


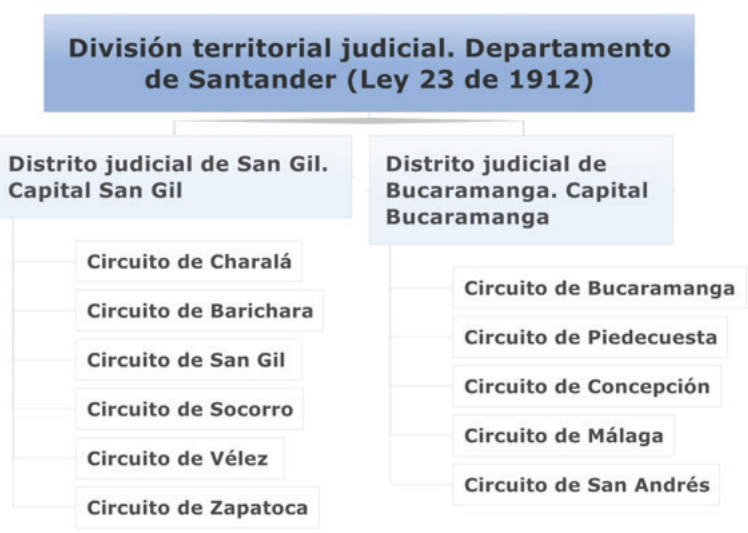

Imagen 3. División territorial judicial Departamento de Santander. Año 1912

Así se consolidó la división territorial de la administración de justicia durante las siguientes dos décadas. En la década de 1930, tras el importante cambio político del ascenso del sector liberal de la clase dominante a ejercer la dominación política sobre el resto de la población, se produjeron una serie de reformas en la administración estatal y en la dinámica de la economía del país que estuvieron acompañados por el auge de una violencia generalizada en el territorio colombiano impulsada y dirigida por los dos partidos tradicionales de la clase dominante en contienda con la resistencia politicopopular. Esto por supuesto incluyó una completa Reforma Judicial. Este proceso de reforma se concretó en la elaboración de unos nuevos códigos en esta materia: Un nuevo Código Judicial, que se sancionó mediante la Ley 103 de 1931; un Código penal, el de 1936, que actualizó el antiguo código de 1863 y finalmente, en 1938 un Código de Procedimiento Penal, que se escindió del cuerpo del Código Judicial en que había estado antes. Todos estos cambios fueron impulsados bajo el espíritu de actualizar la administración de justicia a las nuevas realidades de crecimiento poblacional y de definición de delitos y estuvieron impregnados por las influencias del positivismo jurídico (Gutiérrez, Gutiérrez, 1965, pp. 21-22).

Estas reformas incluyeron cambios en la división territorial judicial. En esta ocasión, el Congreso dio facultades al Poder Ejecutivo para llevar a cabo ese tipo de cambios, que sancionó por medio de un Decreto presidencial (Diario Oficial, 1936, Decreto presidencial 1714). En lo que toca al Distrito Judicial de Bucaramanga, definió los siguientes circutos bajo su jurisdicción: Bucaramanga, Barrancabermeja, Concepción, Málaga, Piedecuesta y San Andrés. Pero de más importancia, este Decreto definió jurisdicciones territoriales diferentes a nivel de Circuito para lo civil y para lo penal. Así, por ejemplo, el Circuito civil de Bucaramanga se conformó con los municipios de Bucaramanga, California, Charta, Floridablanca, Girón, Lebrija, Matanza, Rionegro, Suratá y Tona; mientras que el Circuito penal de Bucaramanga abarcaba los municipios del civil más Cepitá, Los Santos, Piedecuesta y Umpalá.

Este recorrido por los cambios en la legislación relacionada con la división del territorio para la administración de justicia adquiere importancia en la definición de los diferentes fondos que componen la documentación que se está interviniendo. La formalidad de la legislación se contrasta con aquello que se encuentra en el proceso de organización de los expedientes. De esta manera, se obtiene, tras llevar a cabo esta contrastación, el establecimiento de los siguientes Juzgados -concebidos como fondos documentales: 


\section{Tabla 1. Relación de los Fondos identificados en el proceso de organización. Jurisdicción y competencias}

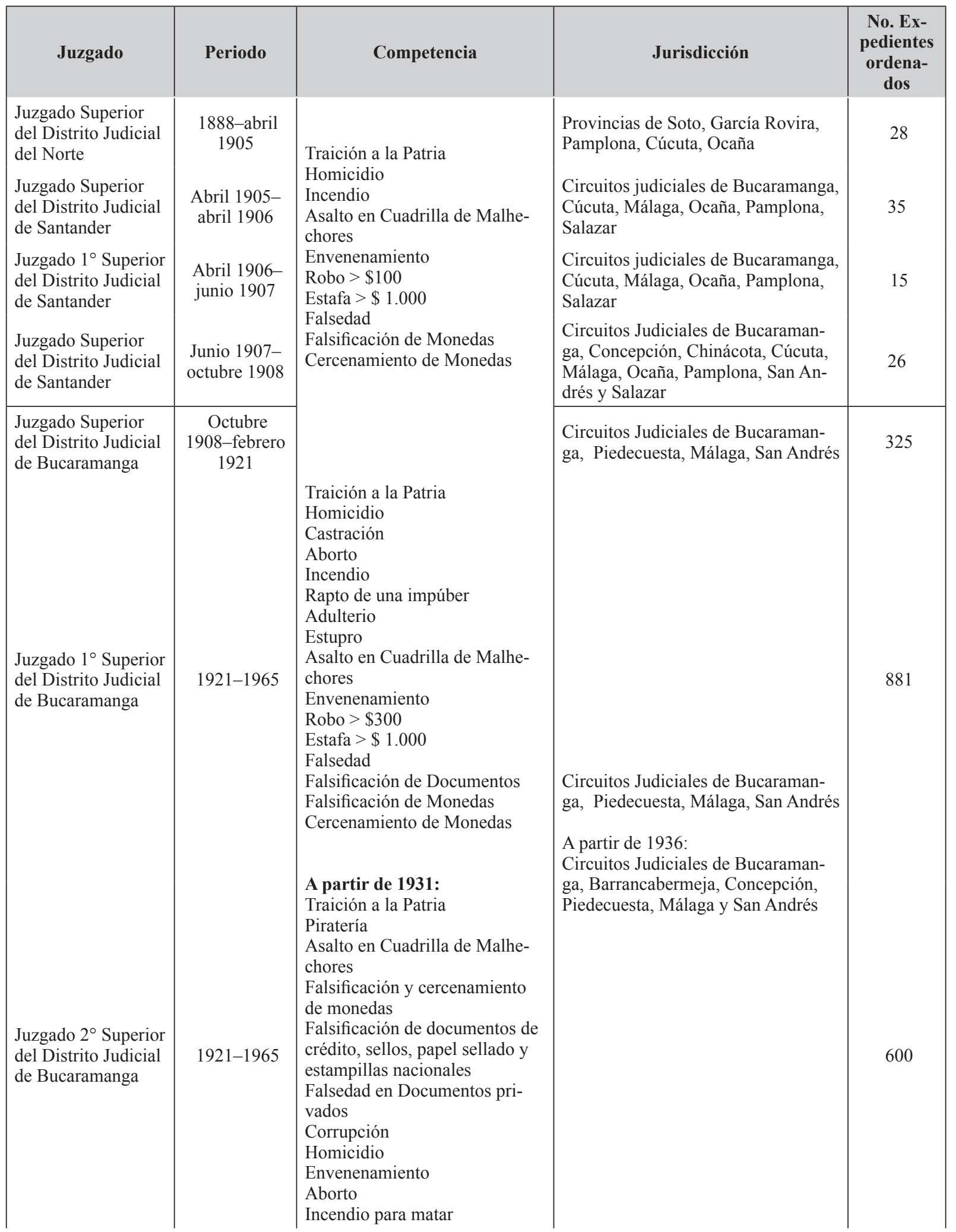


Juzgado $4^{\circ}$ del

Circuito Judicial de

Bucaramanga

Juzgado $1^{\circ}$ del

Circuito Penal de

Bucaramanga

Juzgado $2^{\circ}$ del

Circuito Penal de

Bucaramanga

Juzgado $3^{\circ}$ del

Circuito Penal de

Bucaramanga

Juzgado Municipal de Bucaramanga

Juzgado $1^{\circ}$ Municipal de Bucaramanga

Juzgado $2^{\circ}$ Municipal de Bucaramanga
A partir de 1907:

Delitos contra la propiedad entre $\$ 50$ - $\$ 150$

A partir de 1920:

Delitos contra la propiedad entre $\$ 200$ y $\$ 300$

A partir de 1931:

1903-1936 Causas de responsabilidad contra empleados públicos

Delitos contra la propiedad entre $\$ 150$ y $\$ 300$

Hurto y Robo de ganado mayor de $\$ 300$ o menos

Mudanza o alteración de los

términos o linderos

Junio 1937-

1965

Causas de responsabilidad contra empleados públicos

Delitos contra la propiedad entre $\$ 150$ y $\$ 300$

Junio 1937

1965

Hurto y Robo de ganado mayor de $\$ 300$ o menos

Mudanza o alteración de los

términos o linderos

A partir de 1936:

Junio 1937- Lesiones personales con incapa1965 cidad $>15$ días

A partir de 1886:

Violación de la correspondencia Heridas, golpes y maltratos Daños causados en animales, sembrados y otras propiedades Despojo y uso de propiedades ajenas

1886-1936 A partir de 1907:

Delitos contra la propiedad entre $\$ 20$ y $\$ 50$

A partir de 1920:

Delitos contra la propiedad entre $\$ 50$ - $\$ 200$

A partir de 1931:

En lo civil: Asuntos contenciosos de menor cuantía

Asuntos contenciosos civiles y juicios de sucesión de menos de $\$ 500$

Juicios ordinarios de menor cuantía de $\$ 50$

1938-1944

En lo criminal:

Delitos contra la propiedad entre $\$ 20$ y 150 pesos

Extracción o apertura indebida de correspondencia

Heridas, golpes o malos tratamientos con incapacidad 8 días Uso y daño en propiedades ajenas

1938-1944

\section{A partir de 1936:}

Lesiones personales con incapacidad entre 8 a 15 días
Municipios: Botijas, California, Florida, Girón, Lebrija, Los Santos, Matanza, Piedecuesta, Rionegro, Umpalá, Suratá, Tona, Wilches y

Bucaramanga

A partir de 1912: Se escinden los municipios de Los Santos, Umpalá y Piedecuesta

Municipios: Bucaramanga, California, Charta, Floridablanca, Girón, Lebrija, Matanza, Rionegro, Suratá, Tona, Cepitá, Los Santos, Piedecuesta y Umpalá

Bucaramanga

Bucaramanga 


\begin{tabular}{|c|c|c|c|c|}
\hline $\begin{array}{l}\text { Juzgado } 1^{\circ} \text { Penal } \\
\text { Municipal de Buca- } \\
\text { ramanga }\end{array}$ & 1945-1975 & $\begin{array}{l}\text { En lo civil: } \\
\text { Asuntos contenciosos de menor } \\
\text { cuantía }\end{array}$ & Bucaramanga & 2070 \\
\hline $\begin{array}{l}\text { Juzgado } 2^{\circ} \text { Penal } \\
\text { Municipal de Buca- } \\
\text { ramanga }\end{array}$ & 1945-1965 & $\begin{array}{l}\text { Asuntos contenciosos civiles y } \\
\text { juicios de sucesión de menos } \\
\text { de } \$ 500 \\
\text { Juicios ordinarios de menor }\end{array}$ & Bucaramanga & 5 \\
\hline $\begin{array}{l}\text { Juzgado } 4^{\circ} \text { Penal } \\
\text { Municipal de Buca- } \\
\text { ramanga }\end{array}$ & 1965-1976 & $\begin{array}{l}\text { cuantía de } \$ 50 \\
\text { En lo criminal: }\end{array}$ & Bucaramanga & 258 \\
\hline $\begin{array}{l}\text { Juzgado } 6^{\circ} \text { Penal } \\
\text { Municipal de Buca- } \\
\text { ramanga }\end{array}$ & 1965-1979 & $\begin{array}{l}\text { Delitos contra la propiedad } \\
\text { entre } \$ 20 \text { y } 150 \text { pesos } \\
\text { Extracción o apertura indebida } \\
\text { de correspondencia } \\
\text { Heridas, golpes o malos trata- } \\
\text { mientos con incapacidad } 8 \text { días } \\
\text { Uso y daño en propiedades } \\
\text { ajenas } \\
\text { Lesiones personales con incapa- } \\
\text { cidad entre } 8 \text { a } 15 \text { días }\end{array}$ & Bucaramanga & 140 \\
\hline
\end{tabular}

Dinámica histórica del Cuerpo Auxiliar de la institución judicial

Además de los cambios en la estructura de la institución de administración de justicia, la comprensión del expediente judicial y un adecuado abordaje de éste para los propósitos de la investigación social que propicia, requiere del conocimiento sobre la conformación interna de esta unidad documental. Como se adelantó más arriba, el expediente judicial consta de un conjunto de documentos producidos por diferentes instituciones, los cuales son producidos y ordenados bajo el criterio de las normas legales establecidas para el desarrollo de los procesos judiciales, sean ellos de carácter civil o penal. En lo que sigue va a presentarse la dinámica histórica de dos aspectos del desarrollo de un proceso judicial penal, lo cual que permite contar con herramientas para la comprensión sobre la composición del expediente judicial. Tales aspectos son, por una parte, las instituciones encargadas de la instrucción del sumario, y, por la otra, el papel de la institución de Medicina Legal.

Hasta el año de 1964, para el adelanto del proceso penal por parte de la autoridad judicial, pueden establecerse dos etapas: la instrucción del sumario y el juicio, que se corresponden con dos partes bien definidas en el expediente. La primera debe entenderse como la etapa de investigación encaminada a determinar si un hecho delictuoso ha ocurrido o no, si es constitutivo de delito, y en caso afirmativo, quiénes son sus autores o partícipes. La segunda etapa, la del juicio, está orientada a recaudar la prueba que determina el hecho delictivo específico junto con las circunstancias agravantes y atenuantes en relación a la persona sindicada, y a establecer si hay prueba seria acerca de la responsabilidad de los procesados para proceder a emitir una sentencia. La etapa de juicio corre a cargo de la primera instancia judicial, es decir, la autoridad judicial a quien por mandato legal corresponde el conocimiento del delito específico que se investiga (V. Tabla 1). Esta etapa ha sido siempre competencia de la Rama Judicial, pero los responsables de avanzar en la instrucción, lo correspondiente a la primera etapa definida, fueron variando con el tiempo.

En los artículos 60 y 156 de la Constitución de 1886 se estipuló quiénes podían ejercer el poder judicial y la forma como se organizarían los juzgados y se determinarían sus atribuciones.

Desde entonces hasta el año 1938 el legislador dio invariablemente a las autoridades políticas las calidades de funcionarios de instrucción, sin que se hubiera entendido que se violaba así el precepto constitucional de la separación de los poderes públicos, ni que se agraviara tampoco la norma constitucional que prohíbe reunir en una misma persona la autoridad política o civil con la judicial o militar. Porque se consideró que el funcionario de instrucción no tenía propiamente las funciones de juez sino apenas las de auxiliar o colaborador de la justicia. (Giraldo, 2005, p. 259)

Así, la ley 189 de 1896 confirió el carácter de funcionarios de instrucción al Presidente de la República, a los gobernadores de los departamentos, a los alcaldes municipales y a los inspectores de policía nacional, departamental y municipal. En el caso de Santander, en los municipios que no fueron cabecera de Distrito Judicial, hasta 1945, la instrucción corrió por cuenta de las Inspecciones de policía, las alcaldías y en varias ocasiones, de 
los Juzgados Municipales. Es en Bucaramanga, cabecera de Distrito Judicial, donde puede verse el dinamismo característico del aparato judicial y de las instituciones que le han servido de apoyo para la ejecución de sus tareas. Si bien en este municipio también la Alcaldía y el Juzgado Municipal cumplieron su parte en adelantar la etapa sumarial de los procesos, con la creación en 1916 de la Policía Judicial (Gaceta de Santander, 1916, Decreto presidencial 376), fue la institución policial la principal encargada de asumir la instrucción de los sumarios.

De acuerdo con la información proporcionada por los expedientes judiciales, en 1919 las tareas de instrucción en la capital de Santander fueron asumidas por una nueva entidad, la Oficina de Investigación Criminal, con dependencia de la Policía Departamental de Santander. Esta oficina, en calidad de cuerpo auxiliar del órgano judicial, recibía los denuncios o abría investigaciones de oficio, tomaba declaraciones a testigos e indagatorias a los sindicados, recibía informes de los reconocimientos de los peritos o de los médicos-legistas, según correspondiera; solicitaba antecedentes judiciales de los sindicados, efectuaba careos entre testigos, entre otras diligencias, hasta perfeccionar al mayor grado posible el sumario, para luego remitirlo a los jueces de circuito que fungieron durante todo el período estudiado (1887-1965) como jefes de instrucción ${ }^{2}$, es decir como funcionarios de la rama judicial que ejercían control sobre las autoridades políticas y de policía en lo relativo a la instrucción de los sumarios. Estos, a su vez, determinaban el reparto al juzgado de conocimiento según los criterios de competencia para los diferentes delitos.

Con un nuevo Código de Procedimiento Penal (Ley 94 de 1938), que tuvo como propósito primordial aplicar normas jurídicas universales, producto de la evolución del derecho, con base en principios técnicos de división de funciones y de especialidad en el trabajo, se inhabilitó a las autoridades políticas de las funciones de instrucción de los sumarios en procesos judiciales y ordenó la creación de jueces de instrucción que deberían ser doctores en derecho y con especialización en materia de investigación penal. Tanto el código penal de 1936 como el código de procedimiento penal de 1938 entraron en vigencia el 1 de julio de 1938; sin embargo, debido a las dificultades fiscales para asignar las partidas necesarias para el pago de los cargos que debían crearse, se dispuso que hasta que esto pudiera hacerse continuarían encargados de la instrucción criminal los funcionarios que hasta el momento lo venían haciendo. Esto fue establecido por el Decre-

2 Ley 57 de 1887. to 1111 de 1938, que suspendió los artículos 33, 34, 35 y 36 del código de procedimiento penal.

Así, sólo hasta 1943 mediante la Ley $4^{a}$ se planteó una nueva situación jurídica con la creación de sesenta juzgados de instrucción criminal que se distribuirían en los distintos distritos judiciales del país, tomando en cuenta las estadísticas de criminalidad en cada uno de ellos. Estos juzgados, que pasaban oficialmente a constituir el Cuerpo $\mathrm{Au}$ xiliar del Órgano Judicial, dependerían, desde la sanción de dicha ley, del Departamento de Justicia ${ }^{3}$ del Ministerio de Gobierno. La mayor novedad radicó en que estos Juzgados asumieron la instrucción criminal no sólo en las cabeceras de Distrito Judicial, sino que quedaron encargados de dicha tarea en todos los municipios.

En este mismo sentido, el Decreto extraordinario 650 de 1943 rezaba:

El Cuerpo Auxiliar del Órgano Judicial lo integra la Prefectura Judicial, los Juzgados de Instrucción Criminal, los Juzgados Permanentes y los Jueces de policía. El director del Departamento de Justicia del Ministerio de gobierno ejerce la dirección y vigilancia del Cuerpo Auxiliar del Órgano Judicia".

Así, se daba carácter concreto a la división de los poderes públicos en lo relativo a la administración de justicia, estableciendo instancias con funciones específicas en materia de instrucción de los sumarios para el desarrollo de los procesos judiciales.

Esta tendencia tuvo su mayor profundidad cuando finalmente, en 1964, mediante el Decreto 1356 de 1964, se suprimió la división de instrucción criminal del Ministerio de Justicia con los cargos en ella existentes. Esta norma empezó a regir el 5 de agosto de 1965, mediante el Decreto 1697, lo cual dio paso a la creación de los cargos de fiscales instructores, dependientes de la Procuraduría General y competentes para practicar diligencias investigativas en los procesos penales.

\section{La creación del servicio de Medicina Legal}

En medio de las necesidades de una progresiva eficiencia en la administración de justicia, en los procesos penales se ha hecho cada vez más necesaria la práctica de pruebas médicas que contribuyan al

3 El ministerio de Justicia fue creado por la Ley 63 de 1945. Mediante el decreto 105 de 1947 el gobierno organizó el Ministerio de Justicia y en el artículo 5 dispuso que "todo el personal de jueces y empleados que forman parte del Cuerpo Auxiliar de la Rama Jurisdiccional dependerá en los sucesivo del Departamento Jurídico del Ministerio de Justicia.”. 
esclarecimiento de los delitos. Sin embargo, desde las primeras décadas de la República de Colombia, la medicina científica había permanecido relegada y en competencia con los distintos saberes empíricos, especialmente debido a la pobre existencia de personas formadas profesionalmente. Entendiendo la importancia de la medicina legal para la administración de justicia, el Congreso emitió una serie de leyes mediante las cuales se pretendía promover y regular la práctica de la medicina científica en la ejecución de los procesos penales.

De este modo, mediante la Ley 53 de octubre de 1914 , el Congreso Nacional sancionó la creación del Servicio Nacional de Medicina Legal. Esta Ley fijó que se estableciera en Bogotá la Oficina de Medicina Legal, con un laboratorio de Toxicología y un anfiteatro, oficina que fungiría como la oficina Central de Medicina Legal, que atendería los asuntos de la capital y las consultas que hicieran en última instancia los Tribunales de la Nación, los Juzgados y Tribunales de Cundinamarca. En el caso de los demás departamentos designó la creación de una Oficina de Medicina Legal con sede en la capital de cada departamento, la cual debía estar conformada por dos médicos legistas y un portero escribiente. Estas oficinas departamentales atenderían los asuntos de la respectiva capital, Juzgados y Tribunales de su departamento.

En los municipios en los que no existían Oficinas de Medicina Legal, los médicos podían inscribirse para prestar sus servicios médico-legales, por tanto, cada vez que en la instrucción sumarial de los procesos judiciales se requiriera de estos servicios, el funcionario de instrucción llamaría a dos de los inscritos en su respectivo municipio o en el más cercano. En esta misma dirección se orientó el Decreto Presidencial No. 1 de 1915, por el cual se organizaba el Servicio de Medicina Legal en la nación, en el que además se fijaban los salarios que se asignarían a dichos funcionarios y la responsabilidad del departamento y la Nación en los pagos. Este Decreto establecía, de la siguiente manera, las condiciones en que los funcionarios de instrucción podían solicitar el Servicio de Medicina Legal:

Los funcionarios de instrucción y demás autoridades, sólo podrán exigir la prestación de los servicios de los Médicos Legistas cuando se sospeche o investigue la comisión de un delito. No se considerará, por consiguiente, como servicio de esa naturaleza la sola atestación de defunción que se exija por falta del

4 Ley 53 de octubre de 1914. Gaceta de Santander. Bucaramanga, 30 de enero de 1915. No. 4367. respectivo certificado médico, y por lo mismo no habrá lugar a los honorarios por esa causa. (Diario Oficial, 1915)

Sin embargo, las dificultades para poner en práctica las disposiciones consignadas en la ley 53 de 1914 y el Decreto 1 de 1915 se pondrían de manifiesto en los meses y años posteriores, como expresión del escaso nivel de instrucción de la gran mayoría de colombianos y de la poca capacidad fiscal del Estado para responder a las aspiraciones salariales de quienes sí estaban formados profesionalmente para ejercer dichas funciones. Ejemplos de dicha situación son, por un lado, la misma Ley, en la que se señala la necesidad de abrir en las facultades de medicina la formación de médicos legistas y, por otro, el informe del Secretario de Gobierno de Santander al Gobernador del departamento, en el que expresa las limitaciones en el Servicio de Medicina Legal en Santander en el año de 1917:

Grandes son las dificultades que la efectividad de su prestación ha encontrado en la práctica. En muchas poblaciones faltan médicos graduados; en otras los allí domiciliados no han querido inscribirse como Legistas; y en otras, en fin, los inscritos han retirado sus nombres ante la poca formalidad en los pagos de los servicios prestados. (Gaceta de Santander, Informe de Secretario de Gobierno, 1917)

Otra evidencia de la precariedad del Servicio de Medicina Legal quedó consignada en el mismo informe, cuando el secretario de gobierno expuso la necesidad de que la Asamblea Departamental designara un presupuesto para arrendar un local que pudiera convertirse en anfiteatro, pues

la oficina [de medicina legal] necesita con suma urgencia de un local especial para la práctica de las autopsias, pues está prohibido verificarlas en el Cementerio Católico, lugar que por otra parte no tiene ningunas condiciones de anfiteatro y donde hay que trabajar a la vista de innúmeros espectadores, que acaso acuden tras insanas curiosidades, y donde es casi imposible obtener la reserva de los datos que se recogen, reserva casi siempre indispensable al buen éxito de la investigación judicial. Reparos análogos pueden hacerse al local de la Alcaldía, sobre los inconvenientes especiales que ofrece en relación con la higiene pública, por su situación central en la ciudad y por la carencia absoluta de agua corriente para asearlo cada vez que es necesario. 
Para 1922, la Ley 88 del mismo año dispuso que desde el $1^{\circ}$ de julio de 1923 los gastos del personal de las Oficinas Medico-Legales corrieran por cuenta de los Departamentos y que los gobernadores hicieran los nombramientos de los Médicos-Legistas. Sin embargo, en Santander, no sólo no se había creado la mencionada oficina para llevar a cabo los reconocimientos periciales, las autopsias y demás funciones que debía tener a su cargo, sino que eran los profesores de medicina quienes prestaban casi gratuitamente los servicios de Médicos-Legistas. Frente a esta situación, a través del Decreto No. 26 de 1924 (Gaceta de Santander, N 5048), el Gobernador de Santander determinó el establecimiento de la Oficina Médico-Legal de Bucaramanga, por cuenta del Departamento, y nombró a los doctores Martín Carvajal y David D. M'Cormick médicos de ella, con un canon mensual de sesenta y cinco pesos cada uno.

En el mismo sentido se orientó la Ordenanza No. 4 del 13 de marzo de 1925 (Gaceta de Santander, N ${ }^{\circ}$ 5149), de la Asamblea de Santander, cuando sancionó el funcionamiento de oficinas de Medicina Legal en las ciudades de Bucaramanga, San Gil y Socorro, las cuales estarían servidas por sendos médicos graduados que devengarían un salario mensual de setenta pesos. Estos médicos prestarían sus servicios dentro de los territorios que fueran jurisdicción de los respectivos Juzgados Superiores. El desplazamiento de los médicos fuera de su lugar de residencia se aceptaría sólo cuando no hubiese en los municipios médicos inscritos para desempeñar dichas funciones. En los casos en que los dictámenes debieran ser plurales, los médicos del servicio médico legal podían estar asociados a un médico de asistencia pública.

En 1934 se estableció como función de los médicos legistas del Departamento visitar

las cárceles y los cuarteles de policía del Municipio de su residencia con la regularidad que fuere necesaria para atender debidamente a los enfermos que requieran la asistencia médica, y rendirán un informe mensual al respectivo Prefecto sobre los servicios profesionales prestados en desarrollo de la disposición citada y sobre las condiciones higiénicas de los edificios e indicarán las medidas que estimen convenientes para mejorar su estado sanitario. (Gaceta de Santander, Decreto 468 de 1933)

En los más de 1700 expedientes, ordenados y revisados, que hacen parte de los fondos de los Juzga- dos $1^{\circ}$ y $2^{\circ}$ Superior del Distrito Judicial de Bucaramanga y del Juzgado Superior del Distrito Judicial de Bucaramanga, pudo constatarse que sólo hasta 1943 la Oficina de Medicina Legal de Bucaramanga empezó a emitir informes propios, pues antes de esta fecha los Médicos Legistas debían presentarse en la oficina que estuviese adelantando la instrucción del sumario para rendir ante esta el informe de su evaluación del cadáver o de la escena del crimen.

\section{Conclusiones}

El proceso de organización documental que se encuentra realizando el Grupo de Investigación Historia, Archivística y Redes de Investigación sobre parte de los miles de expedientes judiciales acopiados en el Archivo Histórico de la UIS ha encontrado en la investigación sobre la historia de la administración de justicia una valiosa herramienta para la identificación del flujo histórico del organigrama de la institución judicial en el Departamento de Santander, lo cual ha obrado en positivo para el cumplimiento del principio archivístico básico de la procedencia de los documentos. Así, se ha podido proceder a la identificación de los diferentes juzgados como entidades productoras básicas de los expedientes judiciales. Esto constituye un avance tanto para la continua organización del resto de la documentación judicial que reposa en el Archivo, como un instrumento de referencia en la investigación social de diferente naturaleza.

Esta investigación también ha propiciado una más profunda descripción de la documentación a nivel archivístico. Ha permitido detallar aspectos básicos de los juzgados, como su ubicación en una estructura de administración de justicia, su jurisdicción y las competencias de su labor judicial. También ha podido establecer las partes constitutivas del proceso judicial en lo penal, lo cual implica la identificación de las partes del expediente judicial. Junto con ello, el conocimiento de lo que se ha establecido como el Cuerpo auxiliar de la Institución judicial, ha conducido a identificar las diferentes instituciones que colaboran en la construcción del expediente y del proceso judicial de que es expresión.

El estudio del cambio histórico de la división territorial de la administración de justicia muestra, en primer lugar, la importancia que tuvo el establecimiento del Distrito Judicial como unidad básica territorial judicial, para afianzar el cambio político e institucional en la Regeneración, en el propósito de ordenar el territorio y centralizar el poder político. A su vez, en términos archivísticos, la exis- 
tencia del Distrito Judicial pone las pautas para la organización de la documentación judicial en los tres niveles de juzgados que componen el Distrito: Superior, de Circuito y Municipal. En segundo lugar, este conocimiento permite identificar los cor- tes de los diferentes fondos documentales a lo largo del tiempo y así poder referirse a, por ejemplo, los diferentes Juzgados Superiores que han sido autoridad judicial en el departamento y clasificar en consecuencia la documentación.

\section{Referencias}

Consejo Nacional Legislativo. (1888). Leyes de la República de Colombia expedidas por el Consejo Nacional Legislativo en sus sesiones de 1888. Bogotá, Colombia: Imprenta de vapor de Zalamea Hermanos.

Congreso Nacional. (1905). Constitución política de Colombia. Actos legislativos que la reforman y Leyes de 1905. Bogotá: Imprenta Nacional

Congreso Nacional. (1917). Acto general adicional y reformatorio de la Constitución Nacional y Leyes de 1907. Bogotá: Imprenta Nacional.

Congreso Nacional. (1938). Leyes expedidas por el Congreso Nacional en su legislatura de 1912. Bogotá: Imprenta Nacional.

Congreso Nacional. (1931). Leyes expedidas por el Congreso Nacional en su legislatura de 1931. Bogotá: Imprenta Nacional.

Gobernación de Santander. (1886- 1938). Gaceta de Santander. Bucaramanga, Colombia.

Farge, A. (1991). La atracción del archivo. Valencia, España: Edicions Alfons el Magnànim: Instutició Valenciana D’etudis i Investigació.

Giraldo Ángel, J. (2005). La administración Judicial. En: P. P. Morcillo. (Ed). Historia del Derecho colombiano en la segunda mitad del siglo XX. Tomo VII. Administración de justicia. Bogotá: Universidad Autónoma de Colombia - Ediciones jurídicas Gustavo Ibáñez.

Gutiérrez J y Gutiérrez G. (1965). La Reforma Judicial en Colombia. Bogotá: Ediciones Lerner

Melo, J (2012). Organización de la Administración de Justicia penal en Santander, 1886-1930 (Tesis de Maestría). Universidad Industrial de Santander, Bucaramanga, Colombia

Monotoya, P. (2011). Expedientes criminales e historia del Derecho en Antioquia. Historia y Sociedad, Nº 21 (julio-diciembre 2011), 283-94

Suárez, I., et al (2013). Avances en la organización e historia institucional de fondos judiciales. Archivo Histórico Regional - Universidad Industrial de Santander. Revista electrónica de fuentes y archivos. Centro de estudios históricos "Prof. Carlos S. A. Segreti”. 4 (4): 323-38

Palacio, G. (2002). Archivo histórico judicial de Medellín". Historia y Sociedad, N 8. 315-20

República de Colombia. (1906-1936). Diario Oficial. Bogotá: Imprenta Nacional. 
Justicia Juris, ISSN 1692-8571, Vol. 11. Nº 1. Enero - Julio de 2015 Págs. 26-39

Secretaría de Gobierno de Santander. (1917). Informe al Gobernador del Departamento de Santander. Bucaramanga, Colombia: Gaceta de Santander

Wiesner, L. (comp.) (2002). Los Archivos Judiciales en Colombia. Tunja: Dirección de Investigaciones Universidad Pedagógica y Tecnológica de Colombia. 